\title{
Adipokines, inflammation, insulin resistance, and carotid atherosclerosis in patients with rheumatoid arthritis
}

\author{
Yoon Kang ${ }^{\dagger}$, Hee-Jin Park ${ }^{\dagger}$, Mi-I Kang, Hyang-Sun Lee, Sang-Won Lee, Soo-Kon Lee and Yong-Beom Park
}

\begin{abstract}
Introduction: Cardiovascular (CV) morbidity and mortality are increased in patients with rheumatoid arthritis (RA). Inflammation is thought to be an important factor in accelerated atherosclerosis in RA, whereas insulin resistance is a known risk factor for atherosclerosis in RA. We hypothesised that adipokines could be a link between inflammation, insulin resistance, and atherosclerosis in RA.
\end{abstract}

Methods: The common carotid artery (CCA) intima-media thickness (IMT), CCA resistive index (RI), and carotid plaques were measured by ultrasonography in 192 patients with RA. Insulin resistance was assessed by the homeostasis model assessment for insulin resistance (HOMA-IR). Serum adiponectin, leptin, resistin, tumor necrosis factor-a, and interleukin (IL)-6 concentrations were determined.

Results: The CCA RI was associated with CCA IMT and the estimated total plaque volume after adjustment for conventional CV risk factors. Among adipokines, resistin and IL-6 were correlated with inflammatory parameters. Leptin and leptin:adiponectin (L:A) ratio were correlated with metabolic risk factors, including HOMA-IR. And L:A ratio was related to the CCA RI after adjustment for conventional and nonconventional CV risk factors, including HOMA-IR, erythrocyte sedimentation rate and C-reactive protein.

Conclusion: L:A ratio was associated with HOMA-IR and carotid RI. L:A ratio might be an independent factor for predicting cardiovascular risk in patients with RA.

\section{Introduction}

Cardiovascular (CV) morbidity and mortality are increased in patients with rheumatoid arthritis (RA) [1-3]. However, the pathogenesis of accelerated atherosclerosis in RA is not completely understood, and cannot be explained solely by conventional $\mathrm{CV}$ risk factors such as age, male sex, body mass index (BMI), smoking, lipid profile, hypertension and diabetes mellitus [2,4]. Inflammation is an important nonconventional factor in the increased $\mathrm{CV}$ risk observed in RA [5,6]. Insulin resistance, which is also important in the development and progression of atherosclerotic $\mathrm{CV}$ disease [7], has been suggested as a risk factor for atherosclerosis in RA [8,9]. Insulin resistance is linked to obesity, especially visceral fat accumulation, which alters adipokine secretion

\footnotetext{
* Correspondence: yongbpark@yuhs.ac

†Equal contributors

Division of Rheumatology, Department of Internal Medicine, Yonsei

University College of Medicine, 50 Yonsei-ro, Seodaemun-gu, 120-752, Seoul,

Republic of Korea
}

profiles, and is recognized as a state of adipose tissue dysfunction. On the other hand, insulin resistance contributes to increased systemic inflammation by altering adipokine secretion, which leads to activation of proinflammatory signaling pathways $[10,11]$. Adipokines include adiponectin, leptin, resistin, and some proinflammatory cytokines, such as tumor necrosis factor alpha and interleukin (IL)-6. However, the relationship between adipokine concentrations, inflammation, insulin resistance, and atherosclerosis in patients with RA has not been clearly defined.

The common carotid artery (CCA) intima-media thickness (IMT) had been established as a valid marker of early atherosclerosis [12]. Similarly, the carotid resistive index (RI) correlates with the severity of atherosclerosis [13]. The IMT is a morphological parameter and represents the histologically verified intima-media segment of the vascular wall. In contrast, the RI is a hemodynamic parameter based on Doppler technology and relates to vascular resistance [13]. Whereas the carotid IMT has been 
reported in patients with RA in many studies [14], the RI in these patients has not yet been studied.

We assessed the relationship between adipokines, inflammation, insulin resistance and carotid atherosclerosis via CCA IMT, plaque and RI to test the hypothesis that serum adipokines are a link between inflammation, insulin resistance and atherosclerosis in patients with RA.

\section{Methods}

\section{Study population}

One hundred and ninety-two consecutive patients who were diagnosed with RA at the rheumatology clinic in Severance Hospital, Yonsei University Health System, Seoul, Korea were recruited between September 2011 and January 2012. All patients fulfilled the American College of Rheumatology 1987 revised criteria for classifying RA [15]. Patients with diabetes mellitus were excluded. The study was approved by the Institutional Review Board of Severance Hospital, and patients gave their written informed consent.

\section{Clinical assessments}

Clinical characteristics were assessed on the same day as the carotid ultrasound was performed. Clinical information, including age, sex, and disease duration, history of hypertension, medications, and smoking were assessed by questionnaire. Medications for treatment of RA, including biologics, were assessed by their prescription. Height, body weight, waist circumference, and blood pressure were measured. Tender and swollen joint counts were counted by the same rheumatologist. Disease activities of patients were assessed by the patients' statements of global well-being (via $100 \mathrm{~mm}$ visual analogue scale) and the 28-joint disease activity (via the DAS28 ESR calculator using the erythrocyte sedimentation rate (ESR)).

\section{Laboratory assessments}

Fasting serum insulin, glucose, high-density lipoprotein (HDL) cholesterol, low-density lipoprotein cholesterol, triglycerides (TG), ESR, and C-reactive protein (CRP) concentrations were determined in the hospital clinical laboratory. The homeostatic model assessment for insulin resistance (HOMA-IR) index was calculated. Serum concentrations of adiponectin, leptin, resistin, tumor necrosis factor alpha, and IL-6 were measured using the Lincoplex Milliplex immunoassay (Merck Millipore, Billerica, MA, USA).

\section{Carotid ultrasound}

Both carotid arteries were evaluated with high-resolution ultrasonography (HD15; Philips, Bothwell, WA, USA) with a L12-5 transducer. Three different longitudinal views (anterior oblique, lateral, and posterior oblique) and transverse views of both carotid arteries were obtained.
For IMT measurements, far walls of both the right and the left common carotid arteries $2 \mathrm{~cm}$ downstream from the bifurcation were imaged at the lateral view. QLAB's IMT-quantification software measurement plug-in (Philips Healthcare, DA Best, the Netherlands) was used to increase the consistency and reliability of IMT measurements. The presence of carotid plaque was investigated in the internal carotid artery, the external carotid artery, the bulb and the CCA. The plaque was identified as a discrete projection of $\geq 50 \%$ from the adjacent wall into the vessel lumen. The height and length of a plaque were measured in the longitudinal view, and its width was measured in the cross-sectional view. Plaque volume was estimated automatically by the program plug-in after measuring each length of the three-dimensional axis of the plaque. For RI measurements, a pulsed wave-flow spectrum was recorded and frozen from both middle/distal common carotid arteries after 5 seconds of multiple identical waveforms. The RI was calculated automatically according to the Pourcelot formula as follows [16]:

$\mathrm{RI}=$ (peak systolic velocity - end-diastolic velocity)/ peak systolic velocity

A highly skilled single sonographer, blinded to the subjects' characteristics, performed all examinations throughout the study.

\section{Statistical analyses}

Data were expressed as the median with interquartile range for continuous variables. For categorical variables, counts and percentages were calculated. The relationships between variables were determined by Spearman's correlation analysis because variables were not normally distributed. Multiple linear regression was used to analyze the RI and adjust the confounders: conventional $\mathrm{CV}$ risk factors included age, sex, smoking, systolic blood pressure, BMI, waist circumference, glucose, TG, HDL cholesterol and lowdensity lipoprotein cholesterol; and nonconventional $\mathrm{CV}$ risk factors included inflammatory markers such as ESR and CRP. Statistical significance was considered $P<0.05$. All statistical analyses were carried out using SPSS software (version 19.0; SPSS Inc., Chicago, IL, USA).

\section{Results}

\section{Characteristics of patients with RA}

One hundred and seventy-six patients (91.7\%) were women. The median age of patients was 55 years ( 45 to 62 years). Median disease duration was 9 years (4 to 15 years), median CRP was $1.7 \mathrm{mg} / \mathrm{l}$ ( 0.5 to $5.5 \mathrm{mg} / \mathrm{l}$ ) and median DAS28 ESR was 3.1 (2.5 to 4.1), and most patients in this study had low disease activities of RA. Median BMI was $22.3 \mathrm{~kg} / \mathrm{m}^{2}$ (20.2 to $24.6 \mathrm{~kg} / \mathrm{m}^{2}$ ) and the median HOMA-IR was 1.46 (0.96 to 2.27). Other demographic 
characteristics, clinical data, conventional and nonconventional $\mathrm{CV}$ risk factors, concentrations of adipokines, ultrasonographic measurements and medications of 192 RA patients are summarized in Table 1. The CCA RI, the CCA IMT and concentrations of adipokines did not differ between patients who received biologics and those who did not.

\section{Table 1 Characteristics of patients with rheumatoid} arthritis $(n=192)$

\begin{tabular}{|c|c|}
\hline Age (years) & 55 (45.3 to 62$)$ \\
\hline Women & $176(91.7)$ \\
\hline Disease duration (years) & 9 (4 to 15$)$ \\
\hline ESR (mm/hour) & 35 (20 to 50$)$ \\
\hline CRP (mg/l) & $1.7(0.5$ to 5.5$)$ \\
\hline DAS28 & $3.1(2.5$ to 4.1$)$ \\
\hline TNFa (pg/ml) & $3.8(2.7$ to 5.3$)$ \\
\hline IL-6 (pg/ml) & $2.3(1.7$ to 5.5$)$ \\
\hline Adiponectin ( $\mu \mathrm{g} / \mathrm{ml})$ & $192(136.1$ to 293.7$)$ \\
\hline Leptin (ng/ml) & 7.7 (3.7 to 13.5$)$ \\
\hline L:A ratio $\times 10^{5}$ & $3.64(1.55$ to 8.65$)$ \\
\hline Resistin (ng/ml) & 4.7 (2.4 to 8.3$)$ \\
\hline \multicolumn{2}{|l|}{ Metabolic syndrome features } \\
\hline Metabolic syndrome & $27(14.1)$ \\
\hline Waist circumference (cm) & 77 (72 to 82.4$)$ \\
\hline Glucose (mg/dl) & 86 (81 to 91$)$ \\
\hline Triglycerides (mg/dl) & $94(70$ to 122$)$ \\
\hline HDL cholesterol (mg/l) & 56 (47 to 65.8$)$ \\
\hline $\mathrm{SBP}(\mathrm{mmHg})$ & $124(114$ to 134$)$ \\
\hline Hypertension & $70(36.5)$ \\
\hline HOMA-IR & $1.46(0.96$ to 2.27$)$ \\
\hline \multicolumn{2}{|c|}{ Nonmetabolic cardiovascular risk factors } \\
\hline BMI $\left(\mathrm{kg} / \mathrm{m}^{2}\right)$ & 22.3 (20.2 to 24.6$)$ \\
\hline Total cholesterol (mg/dl) & $184(163$ to 209.8$)$ \\
\hline LDL cholesterol (mg/dl) & $107.2(91.2$ to 129.4$)$ \\
\hline Smoking history & $19(9.9)$ \\
\hline Mean CCA RI & 0.63 (0.60 to 0.66$)$ \\
\hline Mean CCA IMT (mm) & 0.59 (0.51 to 0.68$)$ \\
\hline Total plaque number & $2(1$ to 3$)$ \\
\hline Total plaque volume $\left(\mathrm{cm}^{3}\right)$ & 0.02 (0 to 0.09 ) \\
\hline \multicolumn{2}{|l|}{ Medications } \\
\hline Methotrexate & $189(98.4)$ \\
\hline Leflunomide & $125(65.1)$ \\
\hline Sulfasalazine & $135(70.3)$ \\
\hline Hydroxychloroquine & $92(47.9)$ \\
\hline Biologics ${ }^{a}$ & $43(22.3)$ \\
\hline
\end{tabular}

Values are median (interquartile range) or $n(\%)$.
BMI, body mass index; CCA, common carotid artery; CRP, C-reactive protein; DAS28, Disease Activity Score in 28 joints; ESR, erythrocyte sedimentation rate; HDL, high-density lipoprotein; HOMA-IR, homeostatic model assessment for insulin resistance; IL, interleukin; IMT, intima-media thickness; L:A ratio, leptin:adiponectin ratio; LDL, low-density lipoprotein; RA, rheumatoid arthritis; RI, resistive index; SBP, systolic blood pressure; TNFo,

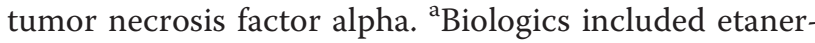
cept, adalimumab and infliximab.

\section{Association of CCA resistance index with CCA intima-media thickness, and plaque}

Significant correlations between CCA RI and CCA IMT and the plaque volume are shown in Table 2. The CCA RI was associated with the mean CCA IMT $(r=0.193$; $P=0.007)$ and the maximum CCA IMT $(r=0.164$; $P=0.023)$. The RI was also associated with carotid plaque volume $(r=0.167 ; P=0.021)$. These correlations remained significant after adjustment for conventional $\mathrm{CV}$ risk factors.

\section{Association of adipokines with inflammation}

Correlations between adipokines and parameters of inflammation are shown in Table 3. Resistin was associated with the ESR $(r=0.322 ; P<0.001)$, CRP $(r=0.209$; $P=0.004)$ and increased disease duration $(r=0.176$; $P=0.014)$. IL-6 was correlated with the ESR $(r=0.450$; $P<0.001)$, CRP $(r=0.468 ; P<0.004)$ and DAS28 ESR $(r=0.448 ; P<0.001)$. Adiponectin was positively correlated with $\operatorname{ESR}(r=0.162 ; P=0.025)$. The associations between resitin and ESR and between IL-6 and ESR and CRP remained significant after adjustment for waist circumference and BMI. Tumor necrosis factor alpha was positively correlated with leptin $(r=0.234 ; P=0.001)$, resistin $(r=0.142 ; P=0.049)$ and leptin:adiponectin ratio (L:A ratio) $(r=0.226 ; P=0.002)$. Adiponectin had a positive association with resistin $(r=0.213 ; P=0.003)$.

\section{Association of adipokines with metabolic risk factors}

Correlations between adipokines and metabolic risk factors are shown in Table 4. HOMA-IR, metabolic syndrome criteria numbers, waist circumference, systolic blood pressure, glucose, TG, and HDL cholesterol were included in

Table 2 Correlation between CCA resistance index with CCA intima-media thickness and plaque volume

\begin{tabular}{lcc}
\hline & $\boldsymbol{r}$ & $\boldsymbol{P}$ value \\
\hline Mean CCA intima-media thickness & 0.193 & $0.007^{*}$ \\
Maximum CCA intima-media thickness & 0.164 & $0.023^{*}$ \\
Total plaque volume & 0.167 & $0.021^{*}$ \\
\hline
\end{tabular}

CCA, common carotid artery. ${ }^{*} P<0.05$ after adjustment for conventional cardiovascular risk factors including sex, body mass index, smoking, systolic blood pressure, triglycerides, high-density lipoprotein cholesterol, and lowdensity lipoprotein cholesterol. 
Table 3 Coefficients of correlation between adipokines and parameters of inflammation

\begin{tabular}{lcccccc}
\hline & L:A ratio & Adiponectin & Leptin & Resistin & TNFa & IL-6 \\
\hline ESR & -0.074 & $0.162^{*}$ & -0.005 & $0.322^{*^{\dagger}}$ & $0.181^{*}$ & $0.450^{*}$ \\
C-reactive protein & -0.041 & 0.137 & 0.026 & $0.209^{*}$ & 0.087 & $0.468^{*}{ }^{+}$ \\
DAS28 ESR & 0.021 & 0.068 & 0.054 & 0.095 & 0.074 & $0.448^{*}$ \\
Disease duration & -0.033 & 0.094 & -0.008 & $0.176^{*}$ & 0.101 & 0.134 \\
\hline
\end{tabular}

DAS28, Disease Activity Score in 28 joints; ESR, erythrocyte sedimentation rate; IL, interleukin; L:A ratio, leptin:adiponectin ratio; TNFa, tumor necrosis factor alpha. ${ }^{*} P<0.05 .{ }^{\dagger} P<0.05$ after adjustment for adiposity including waist circumference and body mass index.

the metabolic risk factors. Leptin and the L:A ratio were associated with multiple metabolic risk factors. Leptin was associated with HOMA-IR $(r=0.369 ; P<0.001)$, Metabolic syndrome criteria number $(r=0.388$; $P<0.001)$, waist circumference $(r=0.488 ; P<0.001)$, and TG $(r=0.264$; $P<0.001)$. The L:A ratio was correlated with HOMA-IR $(r=0.377 ; P<0.001)$, Metabolic syndrome criteria number $(r=0.402 ; P<0.001)$, waist circumference $(r=0.431$; $P<0.001)$, systolic blood pressure $(r=0.164 ; P=0.023)$, TG $(r=0.241 ; P=0.001)$ and HDL cholesterol $(r=-0.169$; $P=0.019)$. The L:A ratio showed a significant correlation with HOMA-IR (Figure 1), and the correlation remained significant after adjusting for conventional $\mathrm{CV}$ risk factors.

\section{Associations of common carotid resistance index with L:A ratio after adjustment for conventional and nonconventional cardiovascular risk factors}

Age, waist circumference, BMI, HOMA-IR, and L:A ratio were associated with increased CCA RI in the univariate linear regression, as shown in Table 5. The L:A ratio was significantly associated with CCA RI after adjustment for age, waist circumference, BMI and HOMA-IR ( $\beta=47.996 \pm$ 22.723, $r=0.036$ ) (data not shown). The L:A ratio remained significantly associated with CCA RI after adjusting for conventional $\mathrm{CV}$ risk factors, and for nonconventional $\mathrm{CV}$ risk factors including HOMA-IR, ESR and CRP $(\beta=49.558 \pm 22.613 ; P=0.030)$, as shown in Table 5 .

\section{Discussion}

Our study showed a clear relationship between the L:A ratio and CCA RI in patients with RA. We found that CCA RI was correlated with CCA IMT and total plaque volume in RA. Among adipokines, resistin and IL-6 were correlated with inflammatory parameters. Leptin and the $\mathrm{L}$ :A ratio were related to metabolic risk factors, including HOMA-IR. The L:A ratio was associated with CCA RI independent of conventional CV risk factors and nonconventional risk factors, including HOMA-IR, ESR and CRP.

The RI is a functional parameter that is easily determined by Doppler sonography in contrast to IMT, a morphological parameter [16]. Before the appearance of morphological alterations that are detectable by the thickening of the intima-media complex, the early form of arteriosclerosis leads to endothelial dysfunction as an exclusively functional disorder characterized by reduced elasticity and increased peripheral resistance [17]. The RI may thus detect the atherosclerotic process as early as observed by IMT. A previous study revealed that the carotid RI predicted the atherosclerosis score and CV mortality and morbidity comparable with the IMT [17]. CV risk factors were independently associated with the carotid RI and IMT [18]. However, the carotid RI had not been previously demonstrated in RA cohorts; this is the first study to measure the carotid RI in RA patients, to our knowledge. In our study, CCA RI was associated with CCA IMT, the estimated total plaque volume independent of

Table 4 Coefficients of correlation between adipokines and parameters related to insulin resistance

\begin{tabular}{|c|c|c|c|c|c|c|}
\hline & L:A ratio & Adiponectin & Leptin & Resistin & TNFa & IL-6 \\
\hline HOMA-IR & $0.377^{* \dagger}$ & -0.113 & $0.369^{*}$ & 0.093 & $0.204^{*}$ & 0.076 \\
\hline MetSyn criteria number & $0.402^{*}$ & $-0.159^{*}$ & $0.388^{*}$ & 0.011 & $0.228^{*}$ & -0.016 \\
\hline Waist circumference & $0.431^{*}$ & -0.094 & $0.488^{*}$ & -0.037 & $0.239^{*}$ & 0.045 \\
\hline SBP & $0.164^{*}$ & -0.068 & 0.119 & 0.033 & 0.112 & -0.001 \\
\hline Glucose & 0.001 & -0.124 & -0.076 & -0.116 & 0.082 & -0.102 \\
\hline Triglycerides & $0.241^{*}$ & -0.102 & $0.264^{*}$ & 0.098 & $0.190^{*}$ & -0.073 \\
\hline HDL cholesterol & $-0.169^{*}$ & $0.261^{*}$ & -0.011 & -0.002 & $-0.189^{*}$ & -0.025 \\
\hline
\end{tabular}

$\mathrm{HDL}$, high-density lipoprotein; HOMA-IR, homeostatic model assessment for insulin resistance; IL, interleukin; L:A ratio, leptin:adiponectin ratio; MetSyn, metabolic syndrome; SBP, systolic blood pressure; TNFa, tumor necrosis factor alpha. ${ }^{*} P<0.05$. ${ }^{\dagger} P<0.05$ after adjustment for conventional cardiovascular risk factors including age, sex, smoking, systolic blood pressure, waist circumference, glucose, triglycerides, HDL cholesterol, and low-density lipoprotein cholesterol. 


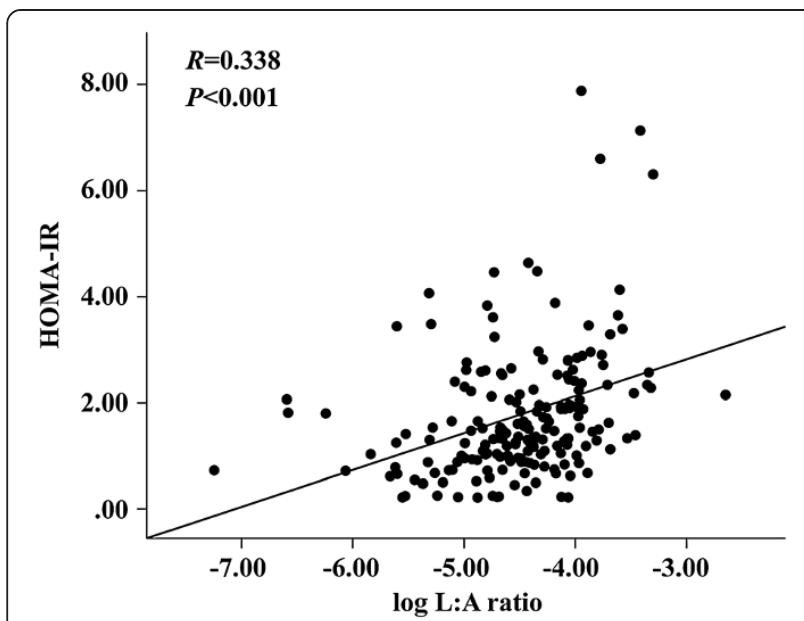

Figure 1 Correlation of the leptin:adiponectin ratio and homeostatic model assessment for insulin resistance. Log leptin: adiponectin ratio (L:A ratio) showed highly significant correlation with homeostatic model assessment for insulin resistance (HOMA-IR) $(r=0.338 ; P<0.001)$, and the correlation remained significant after adjusting conventional cardiovascular risk factors.

conventional CV risk factors. Carotid RI might serve as a marker (complementary to IMT) to signal early atherosclerosis in RA. Further studies will be needed to validate the value of the RI in RA patients.

Leptin and adiponectin are the most abundant adipokines produced by adipocytes. These adipokines are thought to provide an important link between obesity, insulin resistance and related inflammatory disorders [11]. Leptin is known to have proinflammatory and proatherogenic activities $[19,20]$. Leptin concentrations were independently associated with coronary heart disease [21] and predicted $\mathrm{CV}$ events in subjects with coronary atherosclerosis [22]. In contrast to leptin, adiponectin is a protein with insulin-sensitizing properties and antiinflammatory effect [23,24]. Clinical studies identified an association between low serum concentration of adiponectin and CV events [25,26]. Resistin has proinflammatory properties in human [20]. Although studies in animal models consistently show that resistin induces insulin resistance [27], evidence for this effect in humans is less clear. We showed that concentrations of adipokines were associated with systemic inflammation in this study. Resistin and IL-6 were associated with inflammatory markers including the ESR, CRP, DAS28 ESR (only with IL-6) and disease duration (only with resistin). This was consistent with previous reports of serum resistin and IL- 6 being related to systemic inflammation in RA [28-30]. Meanwhile, leptin and adiponectin did not show any associations with inflammatory parameters. This lack of association might be because of relatively low inflammatory burdens of subjects in this study. In addition, adiponectin was positively correlated with resistin. This finding might be due to the compensatory mechanism of adiponectin in the presence of inflammation in RA. Our results supported a recent report that suggested a compensatory increase of adiponectin receptors to counteract the excess inflammatory and atherogenic process in coronary artery disease [31].

In the present study, leptin and the L:A ratio were related to metabolic risk factors and HOMA-IR, consistent with findings that leptin resistance occurred and adiponectin decreased in the insulin-resistant status [32]. Rho and colleagues showed only leptin as being associated with HOMA-IR in RA patients. However, the L:A ratio was reported to be correlated with insulin resistance and to possibly predict the risk of metabolic syndrome in the nondiabetic population $[33,34]$, which might be due to a reciprocal response of leptin and adiponectin to increasing adiposity. Consistent with this, we confirmed an association between the L:A ratio and metabolic risk factors, especially HOMA-IR in patients with RA.

Additionally, the L:A ratio was related to carotid IMT, and was an independent factor for predicting CV disease in healthy population [35]. Meanwhile, only resistin and IL-6 were related to endothelial activation in RA [36,37],

Table 5 Linear regression analysis for associations of CCA resistance index with dependent variables

\begin{tabular}{|c|c|c|c|c|c|c|c|}
\hline \multirow[t]{2}{*}{ Variable } & \multicolumn{3}{|c|}{ Univariate linear regression analysis } & \multicolumn{4}{|c|}{ Multivariate linear regression analysis ${ }^{a}$} \\
\hline & $\beta$ & SE $(\beta)$ & $P$ value & $\beta$ & SE $(\beta)$ & $P$ value & Final model $\left(R^{2}\right)$ \\
\hline L:A ratio & 66.661 & 22.157 & 0.003 & 49.558 & 22.613 & 0.030 & 0.210 \\
\hline HOMA-IR & 0.008 & 0.003 & 0.012 & 0.003 & 0.003 & 0.381 & \\
\hline Age & 0.001 & 0.000 & 0.001 & 0.001 & 0.000 & 0.000 & \\
\hline Waist circumference & 0.002 & 0.000 & 0.000 & 0.001 & 0.001 & 0.064 & \\
\hline BMI & 0.004 & 0.001 & 0.003 & 0.001 & 0.002 & 0.643 & \\
\hline
\end{tabular}

BMI, body mass index; CCA, common carotid artery; HOMA-IR, homeostatic model assessment for insulin resistance; L:A ratio, leptin:adiponectin ratio; SE, standard error. ${ }^{a}$ Multiple linear regression analysis for L:A ratio, conventional cardiovascular risk factors (age, sex, smoking, systolic blood pressure, waist circumference, BMI, glucose, triglycerides, high-density lipoprotein cholesterol, low-density lipoprotein cholesterol, HOMA-IR), and nonconventional cardiovascular risk factors (erythrocyte sedimentation rate and C-reactive protein) and L:A ratio. 
but leptin and adiponectin alone were not related to carotid IMT in patients with RA [38]. We therefore investigated the association between the L:A ratio and carotid atherosclerosis in patients with RA, and revealed that the L:A ratio was independently correlated with the CCA RI, after adjusting for conventional risk factors and nonconventional risk factors, including HOMA-IR. The L:A ratio might be an independent factor for the prediction of CV risk in RA. There are few reports available on the L:A ratio and CV risk in other inflammatory diseases. In patients who were on peritoneal dialysis for end-stage renal disease, the L:A ratio has been reported as being related to mortality secondary to chronic inflammation [39]. The L:A ratio being independently related to $\mathrm{CV}$ risk in $\mathrm{RA}$ is a novel finding.

Little is known about the relationship between adipokines, insulin resistance, and atherosclerosis in patients with RA. Circulating proinflammatory cytokines that secreted from inflamed joints may alter the function of distant tissues (for example, adipose, skeletal muscle, liver, and vascular endothelium) to generate a spectrum of proatherogenic changes that include insulin resistance, prothrombotic effects and endothelial dysfunction [40]. We focused on insulin resistance, one of the pathways that contribute to atherosclerosis in RA, and had hypothesized that adipokines link inflammation, insulin resistance, and carotid atherosclerosis. Insulin resistance maintains some degree of inflammation, and RA itself exhibits persistent inflammation, and both insulin resistance and RA continue to affect CV risk, thus mutually reinforcing each other [41]. This reinforcement could be one mechanism underlying the pathogenesis of accelerated atherosclerosis in RA, and our results support this hypothesis.

\section{Conclusions}

We investigated the overall relationship between adipokines, inflammation, insulin resistance, and the carotid RI in patients with RA. The L:A ratio was significantly associated with HOMA-IR and with carotid RI. Finally, the L:A ratio might be an independent factor for the prediction of $\mathrm{CV}$ risk in RA.

\footnotetext{
Abbreviations

BMI: Body mass index; CCA: Common carotid artery; CRP: C-reactive protein; CV: Cardiovascular; DAS28: Disease Activity Score in 28 joints; ESR: Erythrocyte sedimentation rate; HDL: High-density lipoprotein; HOMA-IR: Homeostatic model assessment for insulin resistance; IL: Interleukin; IMT: Intima-media thickness; L:A ratio: Leptin:adiponectin ratio; RA: Rheumatoid arthritis; RI: Resistive index; TG: Triglycerides.
}

\section{Competing interests}

The authors declare that they have no competing interests.

\section{Authors' contributions}

All authors were involved in drafting or critically reviewing the manuscript. YK and Y-BP participated in the study conception and design. YK, H-JP, S-WL, S-KL, and Y-BP participated in the acquisition of data. YK, H-JP, M-IK, H-SL, S-WL,
$\mathrm{S}-\mathrm{KL}$, and $\mathrm{Y}-\mathrm{BP}$ contributed to the analysis and interpretation of data. All authors read and approved the manuscript for publication.

\section{Acknowledgement}

This study was supported by a grant from the Korea Healthcare Technology R \& D project, Ministry of Health and Welfare, Republic of Korea (A102065).

Received: 28 May 2013 Accepted: 6 November 2013

Published: 19 November 2013

\section{References}

1. Mutru O, Laakso M, Isomaki H, Koota K: Cardiovascular mortality in patients with rheumatoid arthritis. Cardiology 1989, 76:71-77.

2. Del Rincon ID, Williams K, Stern MP, Freeman GL, Escalante A: High incidence of cardiovascular events in a rheumatoid arthritis cohort not explained by traditional cardiac risk factors. Arthritis Rheum 2001, 44:2737-2745

3. Solomon DH, Karlson EW, Rimm EB, Cannuscio CC, Mandl LA, Manson JE, Stampfer MJ, Curhan GC: Cardiovascular morbidity and mortality in women diagnosed with rheumatoid arthritis. Circulation 2003, 107:1303-1307.

4. Dessein PH, Joffe BI, Veller MG, Stevens BA, Tobias M, Reddi K, Stanwix AE: Traditional and nontraditional cardiovascular risk factors are associated with atherosclerosis in rheumatoid arthritis. J Rheumatol 2005, 32:435-442.

5. Bartoloni E, Alunno A, Bistoni O, Gerli R: How early is the atherosclerotic risk in rheumatoid arthritis? Autoimmun Rev 2010, 9:701-707.

6. Ku IA, Imboden JB, Hsue PY, Ganz P: Rheumatoid arthritis: model of systemic inflammation driving atherosclerosis. Circ J 2009, 73:977-985.

7. Despres JP, Lamarche B, Mauriege P, Cantin B, Dagenais GR, Moorjani S, Lupien PJ: Hyperinsulinemia as an independent risk factor for ischemic heart disease. N Engl J Med 1996, 334:952-957.

8. La Montagna G, Cacciapuoti F, Buono R, Manzella D, Mennillo GA, Arciello A, Valentini G, Paolisso G: Insulin resistance is an independent risk factor for atherosclerosis in rheumatoid arthritis. Diabetes Vasc Dis Res 2007, 4:130-135.

9. Pamuk ON, Unlu E, Cakir N: Role of insulin resistance in increased frequency of atherosclerosis detected by carotid ultrasonography in rheumatoid arthritis. J Rheumatol 2006, 33:2447-2452.

10. Berg AH, Scherer PE: Adipose tissue, inflammation, and cardiovascular disease. Circ Res 2005, 96:939-949.

11. Tilg H, Moschen AR: Adipocytokines: mediators linking adipose tissue, inflammation and immunity. Nat Rev Immunol 2006, 6:772-783.

12. Burke GL, Evans GW, Riley WA, Sharrett AR, Howard G, Barnes RW, Rosamond W, Crow RS, Rautaharju PM, Heiss G: Arterial wall thickness is associated with prevalent cardiovascular disease in middle-aged adults. The Atherosclerosis Risk in Communities (ARIC) Study. Stroke 1995, 26:386-391.

13. Frauchiger B, Schmid HP, Roedel C, Moosmann P, Staub D: Comparison of carotid arterial resistive indices with intima-media thickness as sonographic markers of atherosclerosis. Stroke 2001, 32:836-841.

14. Park YB, Ahn CW, Choi HK, Lee SH, In BH, Lee HC, Nam CM, Lee SK: Atherosclerosis in rheumatoid arthritis: morphologic evidence obtained by carotid ultrasound. Arthritis Rheum 2002, 46:1714-1719.

15. Arnett FC, Edworthy SM, Bloch DA, McShane DJ, Fries JF, Cooper NS, Healey LA Kaplan SR, Liang MH, Luthra HS, et al: The American Rheumatism Association 1987 revised criteria for the classification of rheumatoid arthritis. Arthritis Rheum 1988, 31:315-324.

16. Pourcelot L: Applications cliniques de l'examen Doppler transcutane. In Velocimetrie ultrasonore Doppler. 34th edition. Edited by Peronneau P. Paris: INSERM; 1974:213-240.

17. Staub D, Meyerhans A, Bundi B, Schmid HP, Frauchiger B: Prediction of cardiovascular morbidity and mortality: comparison of the internal carotid artery resistive index with the common carotid artery intima-media thickness. Stroke 2006, 37:800-805.

18. Vicenzini E, Ricciardi MC, Puccinelli F, Altieri M, Vanacore N, Di Piero V, Lenzi GL: Common carotid artery intima-media thickness determinants in a population study. J Ultrasound Med 2007, 26:427-432.

19. Katagiri H, Yamada T, Oka Y: Adiposity and cardiovascular disorders: disturbance of the regulatory system consisting of humoral and neuronal signals. Circ Res 2007, 101:27-39.

20. Ouchi N, Parker JL, Lugus JJ, Walsh K: Adipokines in inflammation and metabolic disease. Nat Rev Immunol 2011, 11:85-97. 
21. Wallace AM, McMahon AD, Packard CJ, Kelly A, Shepherd J, Gaw A, Sattar N: Plasma leptin and the risk of cardiovascular disease in the west of Scotland coronary prevention study (WOSCOPS). Circulation 2001, 104:3052-3056.

22. Wolk R, Berger P, Lennon RJ, Brilakis ES, Johnson BD, Somers VK: Plasma leptin and prognosis in patients with established coronary atherosclerosis. J Am Coll Cardiol 2004, 44:1819-1824.

23. Ouchi N, Kihara S, Arita Y, Nishida M, Matsuyama A, Okamoto Y, Ishigami M, Kuriyama H, Kishida K, Nishizawa H, Hotta K, Muraguchi M, Ohmoto Y, Yamashita S, Funahashi T, Matsuzawa Y: Adipocyte-derived plasma protein, adiponectin, suppresses lipid accumulation and class $A$ scavenger receptor expression in human monocyte-derived macrophages. Circulation 2001 103:1057-1063.

24. Yokota T, Oritani K, Takahashi I, Ishikawa J, Matsuyama A, Ouchi N, Kihara S, Funahashi T, Tenner AJ, Tomiyama Y, Matsuzawa Y: Adiponectin, a new member of the family of soluble defense collagens, negatively regulates the growth of myelomonocytic progenitors and the functions of macrophages. Blood 2000, 96:1723-1732.

25. Sattar N, Wannamethee G, Sarwar N, Tchernova J, Cherry L, Wallace AM, Danesh J, Whincup PH: Adiponectin and coronary heart disease: a prospective study and meta-analysis. Circulation 2006, 114:623-629.

26. Pischon T, Girman CJ, Hotamisligil GS, Rifai N, Hu FB, Rimm EB: Plasma adiponectin levels and risk of myocardial infarction in men. JAMA 2004, 291:1730-1737.

27. Steppan CM, Bailey ST, Bhat S, Brown EJ, Banerjee RR, Wright CM, Patel HR, Ahima RS, Lazar MA: The hormone resistin links obesity to diabetes. Nature 2001, 409:307-312.

28. Neumann E, Frommer KW, Vasile M, Muller-Ladner U: Adipocytokines as driving forces in rheumatoid arthritis and related inflammatory diseases? Arthritis Rheum 2011, 63:1159-1169.

29. Senolt L, Housa D, Vernerova Z, Jirasek T, Svobodova R, Veigl D, Anderlova K, Muller-Ladner U, Pavelka K, Haluzik M: Resistin in rheumatoid arthritis synovial tissue, synovial fluid and serum. Ann Rheum Dis 2007, 66:458-463.

30. Klein-Wieringa IR, van der Linden MP, Knevel R, Kwekkeboom JC, van Beelen $E_{\text {, }}$ Huizinga TW, van der Helm-van MA, Kloppenburg M, Toes RE, loan-Facsinay A: Baseline serum adipokine levels predict radiographic progression in early rheumatoid arthritis. Arthritis Rheum 2011, 63:2567-2574.

31. Ikonomidis I, Kadoglou N, Tsiotra PC, Kollias A, Palios I, Fountoulaki K, Halvatsiotis I, Maratou E, Dimitriadis G, Kremastinos DT: Arterial stiffness is associated with increased monocyte expression of adiponectin receptor mRNA and protein in patients with coronary artery disease. Am J Hypertens 2012, 25:746-755.

32. Rho YH, Chung CP, Solus JF, Raggi P, Oeser A, Gebretsadik T, Shintani A, Stein CM: Adipocytokines, insulin resistance, and coronary atherosclerosis in rheumatoid arthritis. Arthritis Rheum 2010, 62:1259-1264.

33. Finucane F, Luan J, Wareham N, Sharp S, O'Rahilly S, Balkau B, Flyvbjerg A, Walker M, Højlund K, Nolan J: Correlation of the leptin:adiponectin ratio with measures of insulin resistance in non-diabetic individuals. Diabetologia 2009, 52:2345-2349.

34. Yun JE, Won S, Mok Y, Cui W, Kimm H, Jee SH: Association of the leptin to high-molecular-weight adiponectin ratio with metabolic syndrome. Endocr J 2011, 58:807-815.

35. Shanker J, Rao VS, Ravindran V, Dhanalakshmi B, Hebbagodi S, Kakkar W: Relationship of adiponectin and leptin to coronary artery disease, classical cardiovascular risk factors and atherothrombotic biomarkers in the IARS cohort. Thromb Haemost 2012, 108:769-780.

36. Dessein $\mathrm{PH}$, Joffe BI: Suppression of circulating interleukin-6 concentrations is associated with decreased endothelial activation in rheumatoid arthritis. Clin Exp Rheumatol 2006, 24:161-167.

37. Dessein PH, Norton GR, Woodiwiss AJ, Solomon A: Independent relationship between circulating resistin concentrations and endothelial activation in rheumatoid arthritis. Ann Rheum Dis 2013, 72:1586-1588.

38. Dessein PH, Norton GR, Badenhorst M, Woodiwiss AJ, Solomon A: Rheumatoid arthritis impacts on the independent relationships between circulating adiponectin concentrations and cardiovascular metabolic risk. Mediat Inflamm 2013, 2013:461-849.

39. Park JT, Yoo T-H, Kim J-K, Oh HJ, Kim SJ, Yoo DE, Lee MJ, Shin DH, Han SH, Han D-S: Leptin/adiponectin ratio is an independent predictor of mortality in nondiabetic peritoneal dialysis patients. Perit Dial Int 2013, 33:67-74.
40. Sattar N, McCarey DW, Capell H, Mclnnes IB: Explaining how 'high-grade' systemic inflammation accelerates vascular risk in rheumatoid arthritis. Circulation 2003, 108:2957-2963.

41. Gremese E, Ferraccioli G: The metabolic syndrome: the crossroads between rheumatoid arthritis and cardiovascular risk. Autoimmun Rev 2011, 10:582-589.

doi:10.1186/ar4384

Cite this article as: Kang et al:: Adipokines, inflammation, insulin resistance, and carotid atherosclerosis in patients with rheumatoid arthritis. Arthritis Research \& Therapy 2013 15:R194

\section{Submit your next manuscript to BioMed Central and take full advantage of:}

- Convenient online submission

- Thorough peer review

- No space constraints or color figure charges

- Immediate publication on acceptance

- Inclusion in PubMed, CAS, Scopus and Google Scholar

- Research which is freely available for redistribution

Submit your manuscript at www.biomedcentral.com/submit
C) BioMed Central 